\title{
AVATAR E OS ESTUDOS CULTURAIS - ALGUMAS OBSERVAÇÕES
}

Klaus EGGENSPERGER - UFPR

\section{Resumo}

Este trabalho discute o mais recente e, provavelmente, o mais bem-sucedido filme hollywoodiano até o momento, Avatar, em relação ao conceito de "cultura" e seus significados básicos. São questionados a idéia da civilização apresentada no filme, a sua forte crítica ecológica e antiimperialista, o problema da identidade cultural e a questão da indústria cultural, da qual o filme é um produto exemplar. Finalmente, defende-se a idéia de um ensino universitário integrativo de literatura e cultura, abrangendo também o campo dos estudos audiovisuais.

Palavras-chave: estudos culturais; indústria cultural; cinema; ensino de cultura

Em seu ensaio A Idéia de Cultura (The Idea of Culture), o teórico britânico Terry Eagleton levanta a questão da transformação histórica da palavra "cultura" e de seus usos contemporâneos. Diante do pressuposto "Se existe cultura como civilidade, cultura como identidade e cultura como comercialização, há também a cultura como protesto radical" (EAGLETON, 2000, p. 181), o autor toma as medidas do amplo campo conceitual e diferencia os significados mais básicos do conceito: cultura como civilização e civilidade, cultura como modo de vida, cultura como mercadoria (fenômeno relativamente novo na história da humanidade) e cultura como crítica. Tais noções podem nos servir de ponto de partida para uma tentativa de avaliação do último filme de James Cameron, Avatar, sob o ângulo dos estudos culturais e vice-versa, considerando também os aspectos que os estudos culturais podem apreender do mais recente blockbuster produzido por Hollywood. 


\section{Civilização e natureza}

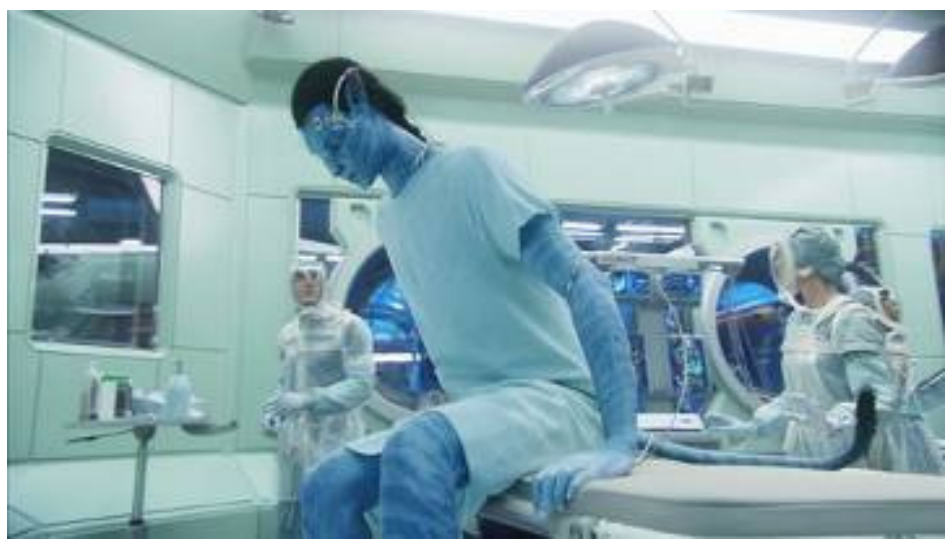

FIGURA 1

A oposição semântica entre cultura e natureza tem origens latinas. A palavra "cultura", como lembrou Alfredo Bosi, é derivada da forma nominal latina cultum que, por sua vez, deriva do verbo colere com o particípio futuro culturus. Colo significa "cultivo (a terra), habito, moro em"; seu particípio passado cultus desemboca no termo religioso "culto", ao passo que "colo é a matriz de colônia enquanto espaço que se está ocupando, terra ou povo que se pode trabalhar e sujeitar" (BOSI, p. 11). Comenta Eagleton: “A cultura, então, herda o manto imponente da autoridade religiosa, mas também tem afinidades desconfortáveis com ocupação e invasão; é entre esses dois pólos, positivo e negativo, que o conceito, nos dias de hoje, está localizado" (EAGLETON, 2000, p. 11). De que forma essa pequena incursão à etimologia da palavra "cultura" poderia estar relacionada ao sucesso mais recente da indústria do cinema norte-americano? Quem assistiu a Avatar sabe que, no centro de sua narrativa há, de um lado, um conflito decorrente do colonialismo agressivo dos terráqueos no planeta chamado Pandora e, de outro, a maneira de viver e as verdades sagradas do povo indígena dos Na'vi. Estratégia e procedimento dos terráqueos do século XXII no filme - que, não por acaso, assemelham-se bastante aos dos norte-americanos contemporâneos -, parecem estar baseados no conceito de civilização do século XIX. Nessa época do imperialismo europeu clássico, a ideia de civilização foi convertida na ideia de progresso com intuito de legitimar o domínio paternalista sobre os "povos selvagens" do mundo não-civilizado, justificando assim o lucro dos capitalistas envolvidos na exploração colonial. Ao mesmo tempo, do filósofo alemão Hegel aos militares republicanos brasileiros, “a grande narrativa do autodesenvolvimento humano" (EAGLETON, 2000, p. 35) encontrava-se em seu auge, e 
passou-se a escrever "cultura" com maiúsculo - era a Cultura formada por grandes obras da literatura, da música, das artes plásticas, entre outros gêneros.

No antigo significado latino de cultivo agrícola, "cultura" significa um cuidar "daquilo que cresce naturalmente, o termo surgere uma dialética entre o artificial e o natural" (EAGLETON, 2000, p. 11). Cada indivíduo humano que nasce necessita de tal cuidado; a cultura, em seu sentido mais amplo, é a segunda natureza do homem, a essência de nossa espécie que as outras não têm. Nesse sentido os $\mathrm{Na}^{\prime}$ vi são, obviamente, humanos, embora cada adulto tenha, aproximadamente, três metros de altura, pele azul e uma grande cauda com a função de um "cabo USB biológico". São criaturas sociais, linguísticas, trabalhadoras, que conhecem crenças, felicidade, sofrimento, e têm história - são, portanto, animais culturais e históricos, tal qual os humanos terrestres.

A representação dos selvagens em Avatar, porém, não remonta à era do imperialismo europeu, mas às idéias iluministas do século anterior. Os Na'vi são humanóides ainda bem próximos do estado da natureza; comparados aos humanos da Terra, que resumem todos os vícios e degenerações do homem civilizado, assemelham-se mais ao homem natural de Rousseau. A lógica do filme mostra uma certa tendência maniqueísta, para a qual o natural é autêntico, bom e verdadeiro, enquanto o lado civilizado parece pérfido, falso e perverso. Paradoxalmente, existem no planeta Pandora uma fauna e uma flora completamente artificiais e fantasmagóricas, geradas digitalmente em computadores, representando o estado da natureza:

Não usamos nenhuma planta real! Muita gente acha que capturamos [as cenas] na Nova Zelândia, porque lá existe floresta subtropical. Pois entramos na floresta - nas férias, para descansar. Capturamos no estúdio. Claro que, criando uma natureza completamente artificial no computador, a nossa celebração do mundo natural em Avatar não deixa de ter um aspecto irônico. Mostramos o nosso respeito à natureza ao trabalhar durante milhares de horas com inúmeros computadores para criar plantas e animais que parecem autênticos e vivos. (CAMERON, 2009, trad. do autor)

Avatar é um exemplo da nova geração de filmes na era digital do cinema de Hollywood, na medida em que, cada vez menos, procura-se capturar uma realidade criada dentro ou fora de um estúdio. Adorno e Horkheimer ainda constataram a perfeição com que as técnicas de cinema "duplicam os objetos empíricos" e, com isso, criam "a ilusão de que o 
mundo exterior é o prolongamento sem ruptura do mundo que se descobre no filme. [...] A vida não deve mais, tendencialmente, deixar-se distinguir do filme sonoro." (ADORNO/HORKHEIMER, 1985, p. 118). Isso mudou pois, hoje em dia, cria-se nos computadores um mundo completamente artificial, por meio de técnicas digitais as mais avançadas. Dessa maneira, a antiga dialética entre o artificial e o natural não desaparece, como alguns teóricos pós-modernos acreditam mas, sim, aparecem num nível bem mais elaborado e complicado do que antes (cf. a discussão da categoria "hiper-realidade" em GEIER 1999).

\section{Identidade}

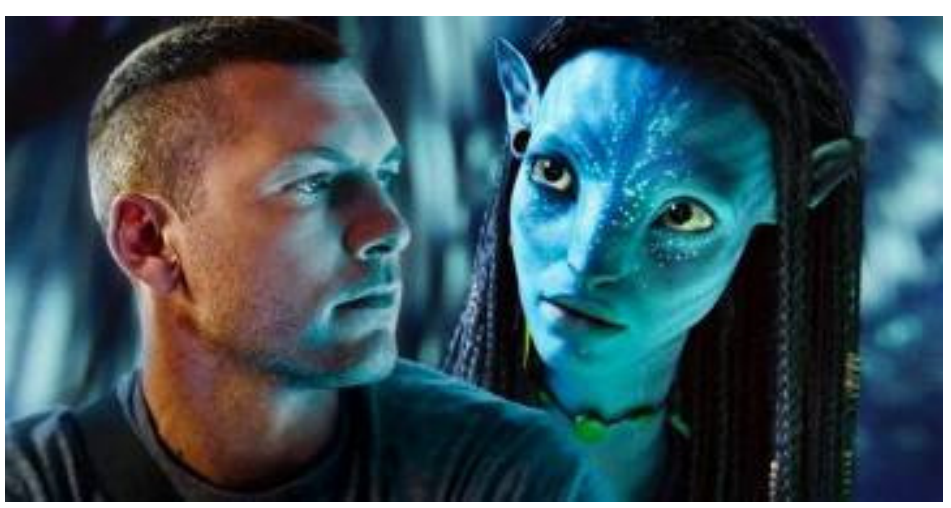

FIGURA 2

A cultura dos Na'vi em Avatar é uma cultura pré-moderna, estável e unificada. "O engano de ver as culturas como mais ou menos coerentes" (EAGLETON 2003, p. 94) tem uma tradição no pensamento europeu que data do iluminismo (cf. YOUNG 2005, cap. 2). O filme apresenta-nos a cultura indígena sob uma perspectiva idealizada, que não combina com a pluralidade e a desigualdade de qualquer cultura real. A relação íntima dos $\mathrm{Na}^{\prime}$ vi com seu ambiente natural, a sua forma de organização social em tribos - com sacerdote e cacique -, a sua maneira de viver e caçar na floresta, indicam que a concepção desse povo foi criada com base na cultura de povos indígenas americanos. Enquanto membros de uma tribo Na'vi, os Omaticaya - indígenas do filme - participam da identidade coletiva e estável, da "root identity" do seu clã, e podem ser tidos como autênticos no sentido de serem espontâneos e de não haver falsidade entre seus integrantes. Tudo isso apresenta uma longa tradição na literatura, com uma vertente mais atual no cinema, sendo que a ficção científica sempre 
recorreu a outros gêneros do cinema, principalmente ao western: “Às vezes, certas obras pertencem à FC somente porque passam em planetas estranhas num futuro remoto; apesar disso apresentam todos os motivos e todas as convenções de um western" (LEDERER, 2008, p. 130).

$\mathrm{Na}$ literatura norte-americana o bom selvagem foi introduzido por James Fenimore Cooper, em seu ciclo The Leatherstocking Tales, acompanhado sempre do selvagem mau, do satanic savage. Basicamente, Cooper oferece aos públicos norte-americano e europeu esses dois estereótipos de índios, ainda que apresente também algumas figuras indígenas individualizadas. ${ }^{1}$

Do outro lado temos a cultura dos humanos, que é marcada por um colonialismo mercantil sem limites. No que se refere a tal cultura, a perspectiva do filme é de um forte malestar: no decorrer da narrativa o espectador descobre, aos poucos, que o modo terrestre de viver e de produzir é perverso. Reina um capitalismo voraz, orientado pela ganância ilimitada, e a civilização humana ocidental é tecnicamente muito superior e, ao mesmo tempo, extremamente devastadora. É hostil à reprodução de culturas locais e de sistemas ecológicos, sendo também autodestrutiva, uma vez que já destruiu a biosfera da terra.

Diferentemente da cultura indígena, a dos terrestres não é homogênea. Além do mandatário dos interesses econômicos da corporação humana que explora o minério do planeta e dos mercenários a seu serviço (que, juntos, representam o complexo militarindustrial americano que já surgira de maneira bem semelhante em Aliens, filme de Cameron de 1986), existe em Avatar um grupo de cientistas. Este também está a serviço da mineradora, mas discorda dos procedimentos do complexo militar-industrial. A personagem principal Jake Sully é um ex-fuzileiro que, de certa maneira, está situado entre os dois grupos humanos; mais notável, porém, é a sua função de controlador do corpo de um Avatar através de conexões neurais. Com isso, ele e os outros poucos controladores levam uma vida dupla, conseguindo realizar o eterno sonho humano de transgredir o próprio corpo, de se transformar num outro, sonho que parece fazer parte da espécie humana. Além da identidade humana coletiva que, no filme, não é algo sólido ou inquestionável, a identidade individual também dá provas de ser fluida: a vida no corpo de um Na'vi e o contato com a tribo levam o herói à percepção do Outro, o que estende a sua identidade humana. Isso não é de se estranhar, visto que a empatia

\footnotetext{
${ }^{1}$ Sobre Cooper, cf. o site da James Fenimore Cooper Society : http://external.oneonta.edu/cooper/, acesso em $12 / 2009$.
} 
é uma capacidade humana básica - empatia com a vida que se apresenta em formato semelhante às experiências terrestres, que leva o espectador à identificação com os estranhos humanóides das telas do cinema, gerados nos computadores da empresa neozelandesa WETA Digital.

A partir de um longo processo de aprendizagem, desde os primeiros contatos até a identificação completa com o povo que o acolhe, o herói decide trocar sua cultura de origem pela cultura estranha. A figura do emissário que cria simpatia por essa cultura estranha, do bom traidor da cultura ocidental/norte-americana não é nova: no cinema, sua melhor realização provavelmente aconteceu em Dance with Wolves, com Kevin Costner e por ele dirigido (USA 1990). Os paralelos dessa produção de duas décadas anteriores com Avatar são bem nítidos e mais fortes do que outros possíveis paralelos, como por exemplo Lawrence of Arabia, filme de 1962, ou The Last Samurai, de 2003.

\section{Resistência}

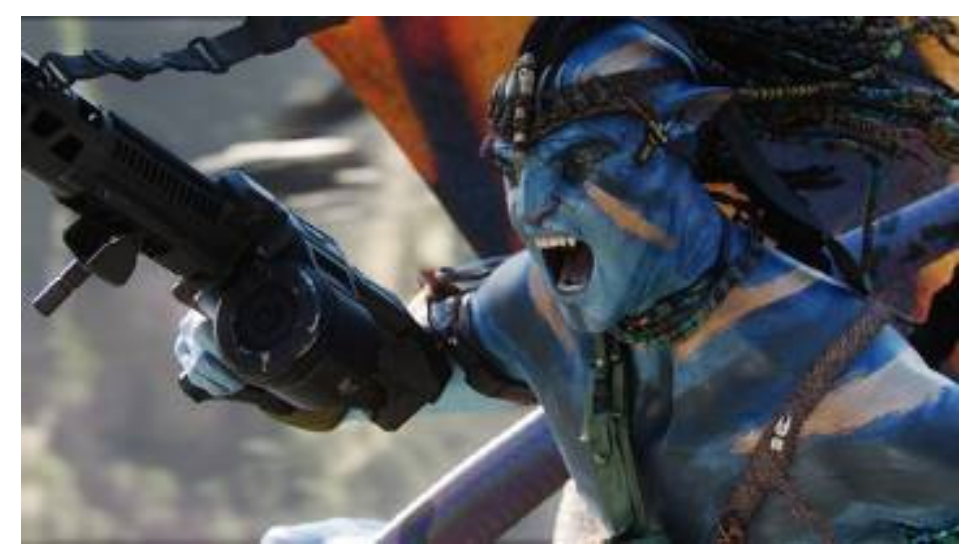

FIGURA 3

Cultura ou Kultur tornou-se, no século XIX, "o nome da crítica romântica prémarxista ao capitalismo industrial primitivo" (EAGLETON, 2000, p. 22). Desde Friedrich Schiller até hoje, a Kulturkritik tem atacado fortemente a civilização moderna. Um exemplo disso é o livro recente da socióloga e historiadora francesa Claudine Haroche, com prefácio brasileiro de Joel Birman, que resume as seguintes tendências nas sociedades contemporâneas mais avançadas: a ascensão triunfante do individualismo extremo, a perda geral dos laços socias, o desenvolvimento da "individualidade desengajada como a contrapartida do 
incremento da desigualdade, da injustiça e da indiferença", e "a exteriorização crescente do sujeito como correlata ao seu empobrecimento interior". Consta-se que "as transformações tecnológicas têm conduzido à inatenção, ao estreitamento da consciência e à falta de simbolização dos sentimentos, que se reduzem às sensações" e fala-se em "perda catastrófica dos pontos de referência simbólicos" (HAROCHE, 2008, p. 15). A autora evidencia o indivíduo contemporãneo "por traços de comportamento e de caráter específicos, como a indiferença, o desinteresse, o desengajamento, a falta de elã, a ausência de espontaneidade, o cálculo permanente, a instrumentalização de si e do outro, os comportamentos fugidios e o desvencilhar-se" (HAROCHE, 2008, p. 127).

Tal diagnose é convincente e não pode ser facilmente questionada; ademais, Avatar não é um filme com a proposta de analisar o indivíduo contemporâneo - foi feito para divertir os indivíduos consumidores do mercado mundial atual, independente de sua nacionalidade, etnia, cultura, classe social etc. Nesse contexto, porém, é deveras interessante notar que o modelo narrativo básico do filme é antigo, podendo ser designado através de um termo pertencente aos estudos culturais anglo-americanos: people against power-bloc. Não se trata somente da luta do povo indígena contra o complexo militar-industrial terrestre; a própria personagem principal também é um “Zé Ninguém”, um ex-fuzileiro jovem, paraplégico e sem recursos que, de repente, recebe a chance de uma segunda vida, uma vida plena de sentido. "O que significa viver bem?" é uma das muitas perguntas que o filme levanta, de maneira indireta, e responde de um jeito popular. O herói que vem do povo não é capaz de grandes discursos (até seu discurso central que antecede a luta, que realiza diante da tribo, é curto e retoricamente pobre), mas sabe agir de maneira correta. Assim já agiu seu precursor 160 anos antes, o herói branco Natty Bumppo de The Leatherstocking Tales, que por sua vez é um pouco mais eloquente:

I know we live in the woods, Hurry, and are thought to be beyond human laws, - and perhaps we are so, in fact, whatever it may be in right - but there is a law and a law-maker, that rule across the whole continent. He that flies in the face of either need not call me a friend." (COOPER, 1841, chapter 1)

O modelo das condutas do herói sempre está baseado numa ética universal (ética cristã, no caso de Cooper e da literatura norte-americana do século XIX), que orienta na hora de decidir a ação certa. Sem isso não existiria a capacidade de agir, agency, como diz um 
termo importante dos estudos culturais anglo-americanos; com isso o indivíduo, juntamente com outros, é capaz de resistir à grande engrenagem colonialista e suas máquinas de dimensões assustadoras. Nesse sentido, o filme passa a lição de que a tendência de evitar qualquer confronto (HAROCHE, 2008, p. 133) é dispensável.

Uma segunda lição da narrativa de Avatar, não tanto para espectadores, mas para certos intelectuais e teóricos de cultura, consiste na máxima simples, porém não raramente esquecida ou negada, de que nem tudo é cultura e redutível ao domínio do simbólico. Há a importantíssima questão sobre quem regula e domina a produção material: por vezes, na base de conflitos considerados culturais - como aquele do filme - está a dimensão material/econômica. Em Avatar trata-se de um típico conflito militar sobre recursos, como muitos que ocorreram nas últimas décadas no Oriente Médio, na África e também na América Latina.

\section{Indústria cultural}

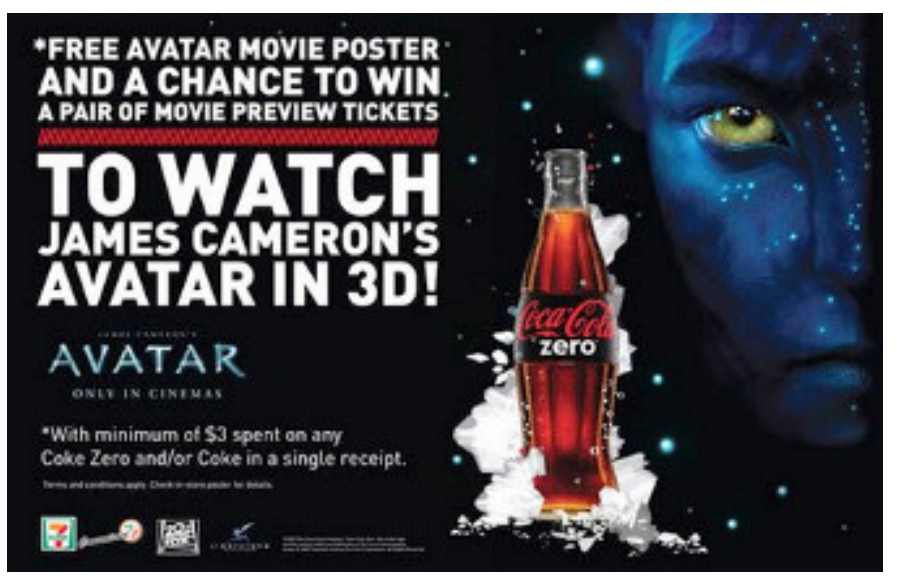

FIGURA 4

Menos uma obra-mestra da sétima arte do que uma da arte da produção digital de uma mercadoria cultural, Avatar é, sem dúvida, um produto exemplar da indústria cultural norteamericana. Poucas semanas depois de seu lançamento em dezembro de 2009, o filme tornouse a maior bilheteria da história do cinema, superando a bilheteria de Titanic, maior sucesso comercial até então, também de James Cameron. Quanto à avaliação da comercialização da cultura por parte dos estudos culturais, estes sempre vacilaram entre dois extremos: de um lado, Adorno e Horkheimer criaram o conceito de "indústria cultural" e explicaram a total 
recusa de tal fenômeno, no famoso capítulo homônimo da Dialética do Esclarecimento (Dialektik der Aufklärung). "Divertir-se significa estar de acordo" (ADORNO/HORKHEIMER, 1985, p. 135), ou seja, de acordo com aquilo que é falso, com uma sociedade cada vez mais inumana. De outro lado, a aprovação acrítica da cultura como mercadoria trabalha com o argumento populista "If the people are ok, then popular culture must be ok." (apud HÜGEL, 2007, p. 74).

A respeito dos estudos culturais na tradição britânica de Raymond Williams e Stuart Hall, é importante sublinhar: "The popular defines a necessary focus and commitment of cultural studies." (Grossberg, apud STÄHELI, 2005, p. 152). O popular é caraterizado por duas dimensões importantes: a conectividade, que deve ser compreensível para todos, e a afetividade, que deve recorrer à emotividade instintiva do consumidor (cf. STÄHELI, 2005, p. 160). A identificação com o popular acontece principalmente no nível afetivo, sem excluir completamente o nível cognitivo. Por sua vez, a mídia visual prossegue aqui com seu princípio de esquematizar tudo. A ótica da emotividade somente existe moldada pelos códigos da indústria cultural, marcada pela padronização e pela produção em série - como, por exemplo, a indústria de automóveis. Nesse sentido, o cinema de Hollywood mudou muito pouco desde os seus inícios; o primeiro beijo entre o avatar de Jake Sully e Neytiri, a filha do cacique, faz parte do velho esquema narrativo do boy meets girl que todos conhecem bem, mas que tem de superar várias dificuldades até conquistar $\mathrm{o}$ amor da moça. Consequentemente, a reação emocional-irônica do público adolescente brasileiro na sala de cinema, que pude observar nesta cena no início do ano de 2010, não foi diferente da reação do público juvenil na sala cinematográfica de uma escola alemã, entre o qual estive presente, quarenta anos antes, diante da cena do primeiro beijo entre Humphrey Bogart e Lauren Bacall, num antigo filme em preto-e-branco.

Comparada à cultura como identidade ou civilização, a cultura como indústria cultural tem, portanto, outro status epistêmico. Mais do que um conceito, é essencialmente uma prática social da qual nada e ninguém escapa, daí a observação: “A cultura contemporânea confere a tudo um ar de semelhança” (ADORNO/HORKHEIMER, 1985, p. 113). Já nos anos quarenta do século passado, Adorno observou "o predomínio que o efeito, a performance tangível e o detalhe técnico alcançaram sobre a obra, que era outrora o veículo da Ideia e, com essa, foi liquidada" (ADORNO/HORKHEIMER, 1985, p. 118). No que diz respeito às 
tendências na indústria cinematográfica das últimas décadas, o sociólogo cultural italiano Alberto Abruzzese pondera a progressiva intensificação sensorial do cinema: o que agora domina é o

espetáculo fílmico que aos poucos pulverizou as narrativas, os roteiros, por meio de uma enorme corrosão de todos os seus elementos estruturais: o personagem como figura de um pacto consensual entre o ponto de vista psicológico e o ponto de vista social; o ambiente geopolítico que opera como pano de fundo da história; os motivos que acionam o mecanismo narrativo, os conflitos a enfrentar, o equilíbrio final a ser alcançado. Tudo isso deixou de compor a trama visual: ela se apresenta, na melhor das hipóteses, como número de circo. (ABRUZZESE, 2009, p. 941)

O estado da técnica mais avançada é explorado a fim de se produzir um cinema de efeitos especiais; o arrebatamento das imagens e dos sons chegou a um nível até agora desconhecido. Abruzzese observa a radicalização da percepção em comparação à narrativa (ABRUZZESE, 2009, p. 942), e Eagleton fala de cultura como gratificação libidinal (EAGLETON, 2000, p. 106), que deixou para trás o modelo burguês clássico da cultura como sublimação. Hollywood tem se tornado uma máquina de excitar e de comover por meio de um sensacionalismo visual que tenta dominar os sentidos dos espectadores e, nesse sentido, o filme Avatar, que estreou simultaneamente em formatos comum e 3-D, não funciona diferente.

Já nos anos quarenta, no que diz respeito a Hollywood, comentou-se a respeito da “compulsão permanente a produzir novos efeitos (que, no entanto, permanecem ligados ao velho esquema)" (ADORNO/HORKHEIMER, 1985, p. 120). Diferentemente dos tempos do studio system hollywoodiano, atualmente os elementos narrativos de base costumam servir simplesmente como fatores de contextualização necessários para colocar o produto à venda (ABRUZZESE, 2009, p. 943). Avatar, porém, é um filme com forte referencial social, e não pode ser reduzido apenas aos seus efeitos visuais. O filme funciona como um conto de fadas que vive da luta antiga entre o bem e o mal. Suas figuras centrais, certamente, não são complexas, e partes do cenário são bem conhecidas até de outros filmes do mesmo diretor².

\footnotetext{
${ }^{2}$ Máqinas de luta antropomórficas já existem no filme de Cameron de 1986, Aliens. Lá é Sigourney Weaver no papel principal de Ellen Ripley, que enfrenta a rainha dos Aliens na luta final dentro de um robô de carregamento. Cameron cita também a estética de máquinas crua dos seus dois filmes do Exterminador do Futuro; ironicamente, em Avatar as máquinas estão do lado dos humanos, destruindo uma civilização considerada inferior.
} 
Além disso, a luta no final configura-se nos moldes da estética de guerra à la Hollywood; contudo, pode-se dizer que, no plano narrativo, expressa uma história empolgante, com uma nítida mensagem antimilitarista, e não um simples pretexto para se exibir efeitos visuais de destruição, como em $O$ Exterminador do Futuro (também de Cameron). Assim, Avatar pode ser considerado um exemplo típico das contradições de um cinema comercial bem feito.

\section{Mídia, memória e ensino}

Um filme popularíssimo como Avatar possibilita o levantamento da questaõ da mercadoria cultural e a sua relação com a memória cultural na sala de aula de língua e cultura. A respeito do ensino escolar - em especial o ensino de inglês -, a situação tem mudado bastante nas últimas décadas, considerando-se que os meios de comunicação social de massa fazem parte do dia-a-dia do ensino de língua, através de canções pop e de rock, de videoclipes, de comics, de reportagens na internet acerca dos astros da cultura popular mundial, entre outros. Muitos professores se esforçam para oferecer material linguísticocultural autêntico e de interesse para a faixa etária de seus alunos; contudo, raramente combinam isso com uma perspectiva crítica, visto que o material utilizado em sala de aula e os livros didáticos têm o intuito apenas de elevar a motivação dos alunos no processo de aprendizagem, e não de questionar uma realidade cultural cada vez mais comercializada. Um estudo empírico aponta: "A consciência crítica é vista pelos professores [de inglês] entrevistados como algo perigoso, na medida em que pode estimular uma aversão pela língua alvo - e isso não é interessante nem para a escola nem para os professores." (LEFFA, 2006, p.12)

No ensino universitário, ao contrário, a palavra "cultura" ainda se escreve com maiúsculo. A transição da Cultura para a cultura durante a primeira metade do século $\mathrm{XX}$ certamente não passou despercebida pelas letras universitárias; estas, porém, assumiram o papel de cuidar da memória cultural e, principalmente, da literatura que, nos últimos três séculos, desempenhava "um papel-chave na formação da subjetividade social" na Europa (EAGLETON, 2000, p. 62). Trata-se de uma função essencial: onde se tomaria conhecimento de Flaubert, Heine ou Manzoni (para citar alguns nomes do século XIX, grande século da literatura burguesa), senão na universidade? O que antigamente ainda fazia parte da formação 
cotidiana da elite e da classe média, hoje em dia, sem o apoio do ensino superior, desaparece completamente, pois o domínio da subjetividade social, da qual Eagleton fala, não se dá mais através da literatura em especial. Mas em tal ponto também se coloca o dilema: limitar o ensino da cultura ao ensino de literatura significa fechar os olhos diante da realidade atual, caraterizada pela forte hegemonia do visual. À medida que a tecnologia e a mídia avançam e novas ordens sociais se instauram com novos paradigmas, valores e linguagens, acontece a ruptura inevitável com o passado.

O passado, por sua vez, nem sempre é aniquilado. As histórias antigas que sobreviveram na memória cultural e que se renovam dentro dela levam, atualmente, uma vida errante nos meios de comunicação social de massas. Nesse sentido, analisar as relações entre a literatura tradicional e a mídia audiovisual moderna na sala de aula universitária pode ser muito gratificante. Que Avatar sirva como exemplo disso: com a tecnologia visual mais avançada disponível no momento, narram-se no filme as velhas histórias de amor e de luta, de desenvolvimento individual e de resistência moral. Figuras como o nobre selvagem e o bom traidor vêm da história cultural de séculos passados. As narrativas e os protagonistas de um escritor romântico como James F. Cooper que, na Europa (França, Inglaterra, Alemanha) já foram muito populares, podem ajudar a entender certos mecanismos básicos do blockbuster americano. Sem a recorrência à memória cultural, até mesmo a gigantesca maquinaria comercial de Hollywood não sobreviveria.

A compreensão crítica das representações e artefatos culturais, sejam eles visuais ou literários, da cultura de massa ou da cultura erudita, consiste em um trabalho que vai além da apreciação ou do prazer que tais representações proporcionam, ao questionar seu papel, suas funções sociais e as relações de poder às quais se vincula. $\mathrm{Na}$ perspectiva dos estudos culturais, que entendem a cultura como signifying practice (Hall, 1997), deveríamos saber analisar os produtos culturais enquanto práticas de produção de significado e sentido, bem como lidar criticamente com os produtos da indústria cultural. Diante do fato de que é certamente muito grande a "distância entre a riqueza da experiência visual na cultura contemporânea e a habilidade para analisar esta observação" (SARDELICH, 2006, p. 211), um professor de língua materna ou de língua estrangeira, hoje em dia, necessitaria não somente de uma formação básica em literatura mas, também, em análise de mídia audiovisual. 


\section{Referências}

ADORNO, Theodor W., HORKHEIMER, Max. Dialética do esclarecimento: fragmentos filosóficos. Rio de Janeiro: Jorge Zahar, 1985.

ABRUZZESE, Alberto. Cinema e romance: do visível ao sensível. In: MORETTI, Franco (org.). O Romance, 1: A cultura do romance. Sâo Paulo: Cosac Naify, 2009, p. 919-948.

BOSI, Alfredo. Dialética da colonização. 4ª ed. São Paulo: Companhia das Letras, 2001.

CAMERON, James. Entrevista com a revista alemã Der Spiegel, 21 de dezembro de 2009. Online http://www.spiegel.de/kultur/kino/0,1518,667576,00.html, acesso 12/01/2010.

COOPER, James Fenimore. The Deerslayer. (1841). Online http://www.gutenberg.org/files/3285/3285-h/3285-h.htm, acesso 12/01/2010

EAGLETON, Terry. A idéia de cultura. Original inglês: The Idea of Culture, 2000. São Paulo: Editora UNESP, 2005. [EAGLETON (2000)]

EAGLETON, Terry. Depois da teoria. Um olhar sobre os Estudos Culturais e o pósmodernismo. Origina inglês: After theory, 2003. Rio de Janeiro: Civilização Brasileira, 2005. [EAGLETON (2003)]

GEIER, Manfred. Fake: Leben in künstlichen Welten. Mythos - Literatur - Wissenschaft. Reinbek bei Hamburg: Rowohlt, 1999.

HALL, Stuart (ed.). Representation: Cultural Representations and Signifying Practices. London: Sage, 1997.

HAROCHE, Claudine. A condição sensível: formas e maneiras de sentir no Ocidente. Rio de Janeiro: Contra Capa, 2008.

HÜGEL, Hans-Otto. Lob des Mainstreams. Zu Begriff und Geschichte von Unterhaltung und Populärer Kultur. Köln: Herbert von Halem, 2007.

LEDERER, Karin. „Hoffen? Sie halten doch die Hoffnung für einen menschlichen Fehler, Mr. Spock?" - Dr. McCoy. Vom utopischen Anspruch in der Science Fiction. In: LEDERER, Karin (ed.). Zum aktuellen Stand des Immergleichen. Dialektik der Kulturindustrie - vom Tatort zur Matrix. Berlin: Verbrecher Verlag, 2008, p. 125-160.

LEFFA, V. J. Língua estrangeira hegemônica e solidariedade internacional. In: KARWOSKI, Acir Mário; BONI, Valéria de Fátima Carvalho Vaz (orgs.). Tendências contemporâneas no ensino de inglês. União da Vitória, PR: Kaygangue, 2006, p. 10-25.

MECHERIL, Paul; WITSCH, Monika. Cultural Studies und Pädagogik: Kritische Artikulationen. Bielefeld: transcript, 2006. 
SARDELICH, Maria Emilia. Leitura de imagens e cultura visual: desenredando conceitos para a prática educativa. In: Educar, n. 27, Curitiba: Editora UFPR, 2006, p. 203-219. Online http://www.iar.unicamp.br/lab/luz/ld/Linguagem\%20Visual/leitura de imagens e cultura vi sual.pdf, acesso 12/01/2010

STÄHELI, Urs. Das Populäre als Unterscheidung - eine theoretische Skizze. In: BLASEIO, Gereon; POMPE, Hedwig; RUCHATZ, Jens. Popularisierung und Popularität. Köln: DuMont, 2005, p. 146-167.

YOUNG, Robert J. C. Desejo colonial. Hibridismo em teoria, cultura e raça. São Paulo: Perspectiva, 2005. 